\title{
Required pecking and refraining from pecking alter judgments of time by pigeons
}

\author{
Thomas R. Zentall and Rebecca A. Singer \\ University of Kentucky, Lexington, Kentucky
}

\begin{abstract}
There is evidence that humans' perception of time is affected by the activity in which they are engaged while they are timing. The more demanding the task, the faster time appears to pass. A similar effect has been found in pigeons. Pigeons trained to discriminate between a short-duration (2-sec) and a long-duration (10-sec) stimulus were required to peck when the stimulus was one color and to refrain from pecking when it was a different color. On probe trials of intermediate durations, the bisection point $(50 \%$ choice of the stimulus associated with both long and short stimuli) for trials in which the pigeons were required to peck was almost 1 sec longer than on trials in which the pigeons were required to refrain from pecking (Zentall, Friedrich, \& Clement, 2006). In the present research, we replicated this effect and determined the relation between this effect and the typical bisection point that occurs when pecking is permitted but not required. Results indicated that the typical procedure results in a bisection point that is between required pecking and refraining from pecking. Furthermore, the rate of pecking when pecking is allowed but not required also falls between the rate of pecking for the required-pecking and refrain-from-pecking conditions. This result suggests that, similar to humans, pigeons underestimate the passage of time when they are active or when attention to time-related cues has to be shared with attention to satisfying the response requirement.
\end{abstract}

Research with humans suggests that the subjectivity associated with judgments of the passage of time may reflect the nature of the additional activities occurring concurrently. The greater the cognitive load of the concurrent activity, the more subjects tend to underestimate the passage of time, whether the intervals being judged are very short (fractions of a second; Chastain \& Ferraro, 1997) or much longer (minutes; Hoekstra, 2005).

Chaston and Kingstone (2004) attributed the subjective compression of time when one is engaged in a demanding task to the relative inattention given to cues provided by the internal clock (see Church, 1978). Specifically, they suggested that the passage of time is judged by the accumulation of pulses coming from the pacemaker. If, because of the cognitive demands of a task, attention is not directed sufficiently at the timing of the interval, Chaston and Kingstone proposed that either the pulse output is slowed or that some of the pulses may be lost (see also Zakay, 1993). In either case, the sum of the accumulator will be less than the actual time that has elapsed, resulting in an underestimation of the passage of time. If attention to an internal clock can also affect subjective timing by animals (see, e.g., Gibbon \& Church, 1984), then one might expect the demands of a task to similarly affect the animals' estimation of the duration of an interval.

Pigeons have been trained to make temporal discriminations in which they must discriminate which of two stimulus durations has occurred, a short interval (e.g., $2 \mathrm{sec}$ ) or a long interval (e.g., 8 sec; Stubbs, 1976). Responses to one test (comparison) stimulus are reinforced following the short sample, and responses to the other comparison stimulus are reinforced following the long sample. To determine the subjective scale of the passage of time on test trials, sample stimuli of various intermediate durations are presented, and the proportion of "long" choices is plotted. The resulting psychophysical function indicates the degree to which each intermediate sample duration is judged as short and long.

When describing the underlying timing scale, the bisection point (the sample duration at which the pigeons are equally likely to choose the comparison that in training had been associated with short and long samples) is of particular interest. The typical finding when such a procedure is used with animals is that the bisection point falls close to the geometric mean of the training durations (Gibbon, 1986; Platt \& Davis, 1983; Stubbs, 1976).

To assess the effect of a variable on the subjective passage of time, one would look for a shift in the bisection point. If subjective time is passing slowly for pigeons, relative to external time, then on a plot of choices of the long-sample-associated comparison, the bisection point would shift to a higher value (to a longer sample duration) because the pigeons would be choosing "short" more than "long" at the geometric mean.

To test the hypothesis that the subjective passage of time is affected by what the pigeon is doing while timing, 
Zentall, Friedrich, and Clement (2006) trained pigeons to discriminate between samples of 2 and $10 \mathrm{sec}$. When the samples were white, for example, the pigeons had to peck the sample at a rate of at least once per sec and then choose the red or green comparison, depending on the duration of the sample. When the samples were blue, the pigeons had to refrain from pecking the sample for its entire duration and then choose the circle or plus comparison, depending on the duration of the sample. On test trials, samples of intermediate duration were presented. Comparison of the two psychophysical functions - one obtained for durations that required the pigeons to peck, the other for durations that required the pigeons to refrain from pecking indicated that the bisection point was shifted almost a full second to the right when pigeons were required to peck. Thus, the results suggested that the pecking requirement resulted in the underestimation of the passage of time.

The purpose of the present experiment was first to replicate the finding that pigeons tend to underestimate the passage of time when they are required to engage in an activity such as pecking (vs. refraining from pecking). The second purpose of this experiment was to compare the bisection points obtained when the pigeons had to peck and when they had to refrain from pecking with the more typical bisection point obtained when pecking is neither required nor prohibited. If pecking per se is responsible for the difference in the bisection points when pecking is required, as opposed to when pecking is not allowed, then the bisection point for the more typical temporal discrimination task in which pecking is allowed but not required should fall between the two other conditions. On the other hand, if it is the "cognitive load" that is responsible for the difference in the bisection points, and refraining from pecking involves less of a cognitive load than does required pecking, then the bisection point for the more typical pecking-allowed condition should occur earlier than for either of the other conditions.

If one assumes that when pecking is allowed, the bisection point would fall at the geometric mean of training durations of 2 and $10 \mathrm{sec}(4.47 \mathrm{sec})$, then it would appear that pecking is the important variable, because Zentall et al. (2006) found that the bisection point was $4.20 \mathrm{sec}$ when pigeons were required to refrain from pecking, whereas it was $5.18 \mathrm{sec}$ when pigeons were required to peck.

However, the assumption that the bisection point typically falls at the geometric mean may not be correct (see, e.g., Kraemer, Brown, \& Randall, 1995; Wilkie, 1987). Thus, the actual bisection point should be determined independently, under essentially the same conditions as are the other psychophysical functions. Comparison of the bisection points for the pecking-allowed and refrain-frompecking conditions will indicate whether the shift in the bisection point results from pecking per se or from the added requirement (i.e., having to peck or refrain from pecking).

\section{METHOD}

\section{Subjects}

The subjects were 10 white Carneau pigeons (Columba livia) that were retired breeders, purchased from the Palmetto Pigeon Plant (Sumter, SC). The pigeons were maintained at $85 \%$ of their free- feeding body weight for the duration of the experiment and were caged individually, with free access to grit and water in the home cage. All of the pigeons were cared for in accordance with University of Kentucky animal care guidelines. The pigeon colony room was maintained on a 12:12-h light:dark cycle. All of the pigeons had previous experience in unrelated studies involving simple simultaneous discriminations.

\section{Apparatus}

The experiment was conducted in a BRS/LVE (Laurel, MD) sound-attenuating pigeon test chamber. The operant chamber measures $32.0 \mathrm{~cm}$ high, $32.0 \mathrm{~cm}$ across the response panel, and $28.0 \mathrm{~cm}$ from the response panel to the back wall. Three round response keys $(2.5 \times 2.5 \mathrm{~cm})$ are aligned horizontally on the response panel and are separated by $1 \mathrm{~cm}$. The bottom edge of the response keys is $25.5 \mathrm{~cm}$ from the wire mesh floor. A 12-stimulus inline projector (Industrial Electronics Engineering, Van Nuys, CA) with 28-V, 0.1-A lamps (GE $1820)$ is mounted behind each response key. The center response key projected blue (Kodak Wratten filter 38) and white (unfiltered) hues. The left- and right-side response keys projected red and green hues (Kodak Wratten filters 60 and 26, respectively). In addition, the side response keys projected a white circle on a black background and a white plus sign against a black background. A houselight located at the center of the chamber ceiling provided general illumination during intertrial intervals. A rear-mounted grain feeder provided mixed grain reinforcement (Purina Pro Grains), with the feeder illuminated through a $5.0 \times 5.5 \mathrm{~cm}$ aperture centered horizontally on the response panel, midway between the response keys and the floor of the chamber. Reinforcement consisted of 2-sec access to mixed grain. An exhaust fan mounted on the outside of the chamber masked extraneous noise. The experiment was controlled and data were collected by a microcomputer located in the adjacent room.

\section{Procedure}

Pretraining. All of the pigeons in the control group $(n=5)$ were pretrained to ensure that they would peck blue and white samples on the center key, and red, green, circle, and plus comparisons on the side keys. All responses were reinforced with 2-sec access to mixed grain.

Pigeons in the experimental group were pretrained to ensure that they would peck all of the comparison stimuli and only one of the two samples (white or blue). Three of the pigeons were trained with the blue sample on the center key, and the remaining pigeons were trained with the white stimulus. In each case, once the pigeon pecked at each stimulus, the sample peck requirement was gradually increased to 10 pecks (FR10).

Training. On each training trial, a blue or white sample stimulus was presented for 2 or $10 \mathrm{sec}$. Pigeons in both the experimental and control groups were presented with blue samples followed by circle and plus comparisons, and by white samples followed by red and green comparisons. If the blue sample was illuminated for $2 \mathrm{sec}$, then choice of the circle comparison was reinforced and choice of the plus comparison resulted in trial termination. If the blue sample was illuminated for $10 \mathrm{sec}$, then choice of the plus comparison was reinforced and choice of the circle comparison resulted in trial termination. If the white sample was presented for $2 \mathrm{sec}$, then choice of the red comparison was reinforced and choice of the green comparison resulted in trial termination. If the white sample was presented for $10 \mathrm{sec}$, then choice of the green sample was reinforced and choice of the red sample terminated the trial. A 10 -sec intertrial interval separated the trials. An example of the trial types presented in this experiment appears in Figure 1.

Pigeons in the experimental group were also required to meet a peck requirement to the sample before being presented with the comparison stimuli. Pigeons that had been pretrained to peck at the white stimulus were required to make a minimum of 2 pecks to 2 -sec white samples and a minimum of 10 pecks to 10 -sec white samples. Failure to meet the sample requirement led to the termination of the trial, followed by a dark intertrial interval and the restart of the trial until the peck requirement was met. Only trials that ended in the presentation of comparison stimuli were counted as trials. 


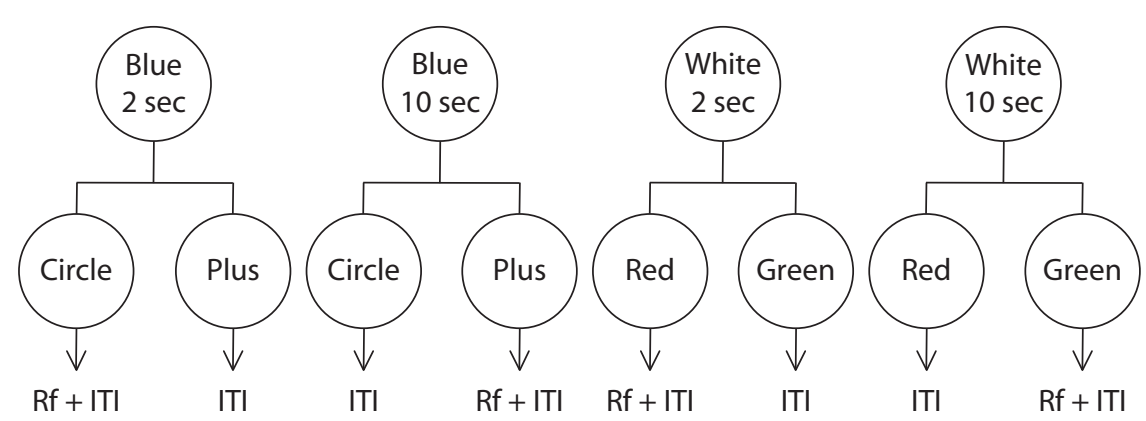

Figure 1. Trial types for the experimental group and the control group. For 3 pigeons in the experimental group, when the center key was blue, the pigeons had to peck at least once per second to light the comparison keys. When the center key was white, the pigeons had to refrain from pecking for 2 or 10 sec to light the comparison keys. For the remaining pigeons in the experimental group, when the center key was white, the pigeons were required to peck once per second, but when it was blue, they were required to refrain from pecking. Pigeons in the control group were allowed to peck both blue and white samples, or could refrain from pecking. Rf, reinforcement; ITI, intertrial interval.

On blue sample trials, pigeons were required to refrain from pecking for $2 \mathrm{sec}$ on 2-sec sample trials and to refrain from pecking for $10 \mathrm{sec}$ on 10 -sec sample trials. Failure to withhold pecks resulted in immediate trial termination, followed by a 10 -sec dark intertrial interval and restart of the trial until the no-peck requirement was met. The absence of pecking on these trials led to presentation of circle and plus comparisons. The choice of the circle on 2-sec sample trials and the plus on 10 -sec sample trials led to reinforcement. For the remaining pigeons, the response requirements (pecking or refraining from pecking) on white and blue sample trials were reversed. For all pigeons, incorrect comparison choices led to termination of the trial followed by a 10 -sec dark intertrial interval and restart of the trial, to a maximum of five repeats per trial (a correction procedure).

Each training session consisted of 96 trials (not counting repeats): 24 trials each of 2-sec white sample trials, 10 -sec white sample trials, 2-sec blue sample trials, and 10-sec blue sample trials. All of the pigeons remained in training until they reached a criterion of $85 \%$ matching accuracy on each of the four trial types for two consecutive sessions.

Testing. Testing sessions consisted of 48 training trials and 56 test trials. During continued training trials, the training contingencies were in effect for sample pecking or refraining from pecking on 2- and 10 -sec sample trials, but a noncorrection procedure was used for comparison choice. On test trials, an equal number of blue and white samples were presented for $2.45,2.99,3.66,4.47,5.47,6.69$, and $8.18 \mathrm{sec}$. These values were selected because they represent equal $\log$ units between 2 and $10 \mathrm{sec}$. There was no peck requirement on these test trials, and reinforcement was delivered on $50 \%$ of the trials, independently of the subjects' choices. In all other respects, test trials were similar to training trials. The pigeons were tested for five consecutive test sessions. Thus, the pigeons were tested with white and blue samples at each of the seven testing sample durations, for a total of 20 test trials each. Training and test trials were presented in random order.

Bisection points were estimated from test trials for each pigeon in the experimental group both on trials on which they were required to peck the sample and trials on which they were required to refrain from pecking the sample, and also for each pigeon in the control group. The bisection points were estimated in two ways. First, the bisection point was estimated by finding the longest sample duration $(t)$ for which choice of the long comparison was less than $50 \%$ and calculating the proportion of the next interval that was below $50 \%$ and adding that proportion to $t$. A second bisection point was estimated by finding the best-fit logistic function for the data for each pigeon and determining the sample duration at which the logistic function crossed the $50 \%$ choice criterion. For all analyses, the .05 level of statistical significance was adopted, and all $t$ tests were two-tailed.

\section{RESULTS AND DISCUSSION}

\section{Acquisition}

Pigeons in the control group reached the acquisition criterion in an average of 74.2 sessions, with considerable variability ( $S E M= \pm 25.4)$. Those in the experimental group reached the acquisition criterion for samples that they were required to peck in an average of 50.8 sessions $(S E M= \pm 11.0)$, and when they were required to refrain from pecking the sample, in an average of 50.6 sessions $(S E M= \pm 11.1)$. A correlated $t$ test performed on the acquisition scores indicated that the difference in sessions to criterion for the temporal discrimination that required pecking and the temporal discrimination that required the absence of pecking was not statistically significant $(t<1)$. A $t$ test performed on the acquisition scores, comparing the control group with the required-pecking condition, also was not statistically significant $(t<1)$. Finally, a $t$ test performed on the acquisition scores, comparing the control group with the refrain-from-pecking condition, also was not statistically significant $(t<1)$. Thus, there is little evidence that it took the pigeons longer to acquire the temporal discrimination when they were required to peck or were required to refrain from pecking than when pecking was allowed but was not required.

\section{Testing}

Training discrimination. Temporal matching accuracy was comparable in the pecking-required $(88.2 \%$ correct) and pecking-allowed ( $85.8 \%$ correct) conditions, but it was a bit lower in the refrain-from-pecking condition $(81.5 \%$ correct). A two-way repeated measures analysis performed on discrimination performance during testing, with sample condition (required pecking vs. refrain from pecking) and sample duration (2 vs. $10 \mathrm{sec}$ ) as factors indicated no significant effects of sample duration $(F<1)$ or sample condition $[F(1,9)=3.36, p>.05]$, 
and no sample duration $\times$ sample condition interaction $[F(1,9)=1.29, p>.05]$. A two-way mixed factors analysis performed on discrimination performance during testing on the required-pecking versus pecking-allowed condition and sample duration ( 2 vs. $10 \mathrm{sec}$ ) also indicated no significant effects: sample duration $[F(1,8)=1.90, p>$ $.05]$, sample condition $(F<1)$, and sample duration $X$ sample condition interaction $(F<1)$. A similar analysis performed on discrimination performance during testing on the pecking-allowed versus refrain-from-pecking condition and sample duration ( 2 vs. $10 \mathrm{sec}$ ) also indicated no significant effects: sample duration $(F<1)$, sample condition $[F(1,8)=3.69, p>.05]$, and sample duration $\times$ sample condition interaction $(F<1)$. Thus, in spite of some variability, matching performance was comparable for the three conditions at the 2 - and 10 -sec training values during testing.

Psychophysical functions: Raw data. Psychophysical functions were plotted as percentage choice of the comparison associated with responses to the long sample for the three conditions (refrain from pecking, pecking allowed, and pecking required); they appear in Figure 2. As can be seen in the figure, the bisection point came earliest for pigeons when they were to refrain from pecking and latest for pigeons when they were required to peck. For pigeons in the control group for which pecking was allowed but not required, the bisection point came in between the two bisection points for pigeons in the experimental group.

An ANOVA performed on the psychophysical functions for the pigeons in the experimental group, with condition (required pecking vs. refrain from pecking) and sample duration as factors, indicated that there was a significant effect of sample duration $[F(8,72)=205.19, p<.001]$ and a marginal effect of condition $[F(1,9)=3.72, p=.08]$. More important, there was a significant sample duration $\times$ con-

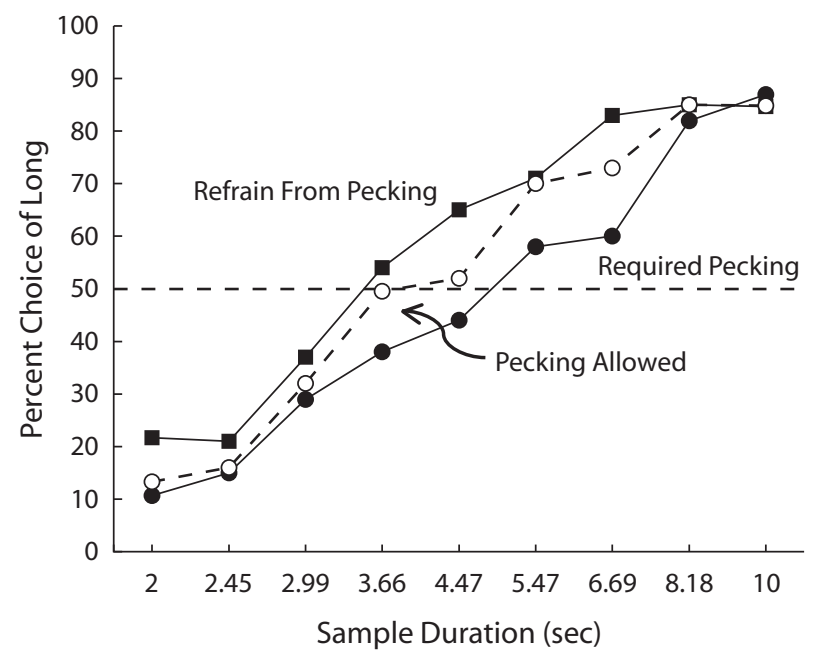

Figure 2. Psychophysical sample-duration functions for the experimental pigeons that were required to peck in the presence of one color (filled circles, solid line) and required to refrain from pecking in the presence of the other color (filled squares, solid line). Control pigeons were allowed to peck or not peck (open circles, dashed line).

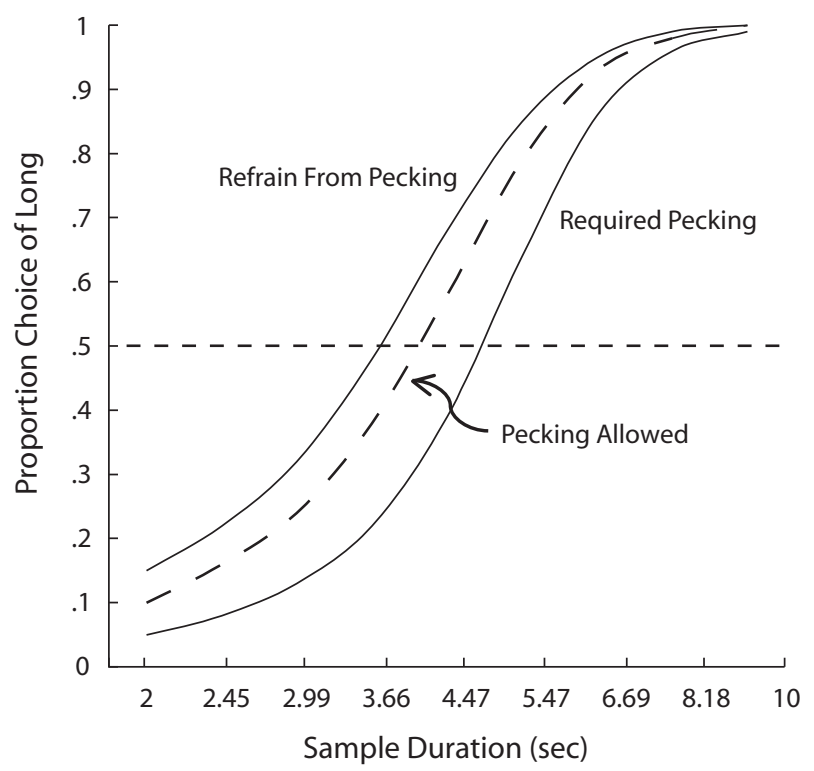

Figure 3. Best-fit logistic functions (one free parameter) calculated for each pigeon in the pecking-allowed condition, peckingrequired condition, and refrain-from-pecking condition.

dition interaction $[F(8,72)=8.81, p<.001]$. The absence of a significant effect of condition can be attributed to the fact that matching accuracy was constrained at 2- and 10sec sample durations because of ceiling and floor effects, respectively. That is, the pigeons were trained to criterion at those values. Thus, the significant interaction reflects the difference in the psychophysical functions primarily at sample durations in the middle portion of the function.

The calculated mean bisection points for the three conditions were $3.74 \mathrm{sec}$ for the refrain-from-pecking condition, $4.15 \mathrm{sec}$ for the pecking-allowed condition, and $5.03 \mathrm{sec}$ for the pecking-required condition. Relative to the pecking-allowed condition, the bisection point for the required-pecking condition was higher and the bisection point for the refrain-from-pecking condition was lower. A correlated $t$ test performed on the calculated bisection points for the pecking-required versus refrain-frompecking conditions indicated that the difference was statistically significant $[t(4)=3.44, p=.03]$. Independent groups $t$ tests performed on the bisection points from the pecking-required versus the pecking-allowed conditions and the refrain-from-pecking versus pecking-allowed conditions were not significant, however $[t(8)=1.86$, $p>.05$, and $t(8)=1.15, p>.05$, respectively].

Psychophysical functions: Logistic functions. Bestfit logistic functions were then calculated for each pigeon in the refrain-from-pecking condition, the peckingallowed condition, and the pecking-required condition, using the following equation with one free parameter:

$$
f(x)=\frac{1}{1+b^{-x}}
$$

The mean best-fit logistic functions appear in Figure 3 . Again, the psychophysical functions are orderly, with the bisection point for the refrain-from-pecking function oc- 
curring before the bisection point for the pecking-allowed function, and the bisection point for the pecking-required function occurring after the bisection point for the pecking-allowed function. To further clarify the relation between the condition and the bisection point, the three mean bisection points calculated from the logistic functions for each condition are shown in Figure 4.

A correlated $t$ test performed on the bisection points for the experimental pigeons calculated from the logistic functions indicated that the bisection point for the refrainfrom-pecking condition, $3.74 \mathrm{sec}$, came significantly earlier than the bisection point for the pecking-required condition, $5.03 \mathrm{sec}[t(4)=2.84, p=.046]$. An independent sample $t$ test performed on the bisection points calculated from the logistic functions for the pecking-required condition and the pecking-allowed condition, $4.15 \mathrm{sec}$, indicated that the difference was also significant $[t(8)=$ $2.60, p=.030]$. A second independent sample $t$ test performed on the bisection points calculated from the logistic functions for the refrain-from-pecking condition and the pecking-allowed condition indicated that the difference was not significant $[t(8)=1.20, p>.05]$. Finally, as expected, the Pearson product-moment correlation between the bisection point calculated from the raw data for each subject and the bisection point based on the logistic function for each subject $(r=.84)$ was quite high.

Sample pecking. When sample pecking for the three conditions at the 2- and 10-sec sample durations was examined during testing, it was found to reflect the task require-

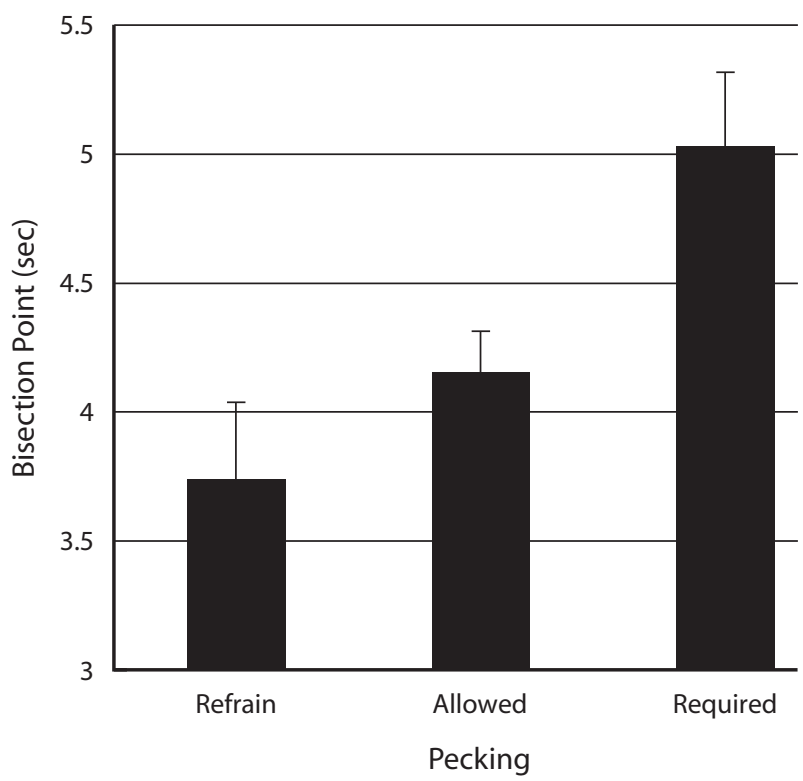

Figure 4. Calculated mean bisection point based on the logistic functions for pigeons in the experimental group on test trials on which the pigeons were required to peck the sample at least once per sec (required) and for test trials on which they were required to refrain from pecking the sample (refrain), and for pigeons in the control group that were allowed to peck the sample but not required to peck (allowed). All pigeons were trained to discriminate between 2-and 10-sec samples. Error bars represent the standard error of the mean.

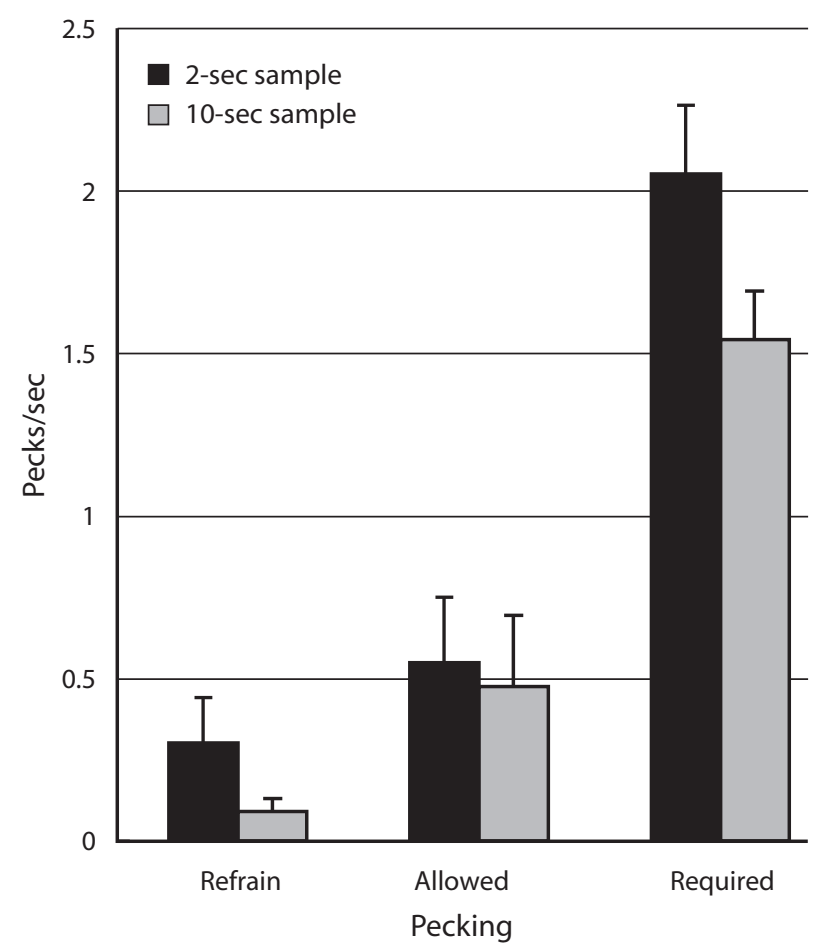

Figure 5. Rate of sample pecking for pigeons in the experimental group on test trials on which the pigeons were required to peck the sample at least once per sec (required) and for test trials on which they were required to refrain from pecking the sample (refrain), and for pigeons in the control group that were allowed to peck the sample but not required to peck (allowed). Rate of sample pecking is shown separately for 2- and 10-sec samples. Error bars represent the standard error of the mean.

ments. The rate of pecking was highest for the peckingrequired condition, lowest for the refrain-from-pecking condition, and intermediate for the pecking-allowed condition. The pecking rate for each condition on 2-sec sample and 10-sec sample trials appears in Figure 5.

A two-way, mixed-factor ANOVA performed on the pecking-rate data from pecking-required and peckingallowed trials indicated there was a significant effect of pecking requirement $[F(1,8)=18.22, p=.003]$, but not a significant effect of sample duration $[F(1,8)=1.77, p>$ $.05]$, or pecking requirement $\times$ sample duration interaction $(F<1)$. A second two-way, mixed-factor ANOVA performed on the pecking-rate data from refrain-frompecking and pecking-allowed trials indicated no significant effects of pecking requirement $[F(1,8)=2.94, p>$ $.05]$, sample duration $(F<1)$, or pecking requirement $\times$ sample duration interaction $(F<1)$.

Separate $t$ tests performed on the pecking data from the three conditions for the two sample durations indicated that the pigeons pecked at a significantly faster rate on 2 -sec than on 10-sec sample trials in the pecking-required condition $[t(4)=3.22, p=.03]$, but not in the peckingallowed condition $[t(4)<1]$, or refrain-from-pecking conditions $[t(4)=1.66, p>.05]$. Faster pecking on 2-sec sample trials in the pecking-required condition suggests 
that the rate of pecking tapered off during the 10 -sec sample trial in this condition.

Sample pecking on trials at each of the test durations as well as at the training durations for each of the conditions is presented in Figure 6. As can be seen in Figure 6, in the pecking-required condition, the rate of pecking was highest on 2- and 10-sec trials. This is not surprising, because those were the durations on which the pigeons were trained. Thus, when the pigeons were required to peck, they made a burst of responses at the start of each trial; then, if the sample stayed on, they made another burst of responses at the end of the trial.

The pattern of sample pecking in the pecking-allowed condition was somewhat different. Because presentation of the comparison stimuli was not contingent on sample pecking, in general, the pigeons pecked at a relatively low rate (about $0.5 \mathrm{pecks} / \mathrm{sec}$ ) throughout the trial, regardless of its duration. As expected, the rate of sample pecking in the refrain-from-pecking condition was quite low (between .25 and .09 pecks per sec), independent of sample duration.

Correlation between bisection point and sample pecking. The relation between the bisection point and the pecking rate for the three conditions can be seen in Figure 7. The fact that the refrain-from-pecking data and the peckingrequired data come from the same subjects but the peckingallowed data come from different subjects precludes the direct statistical comparison of the three conditions. A Pearson product-moment correlation performed on the bisection point and pecking rate data from the pecking-required and refrain-from-pecking conditions indicated that there was a significant correlation $\left[r^{2}(8)=.39, p=.05\right]$. The best-fit linear function describing that correlation, $x=$ $.656 y+3.73$, is also presented in Figure 7.

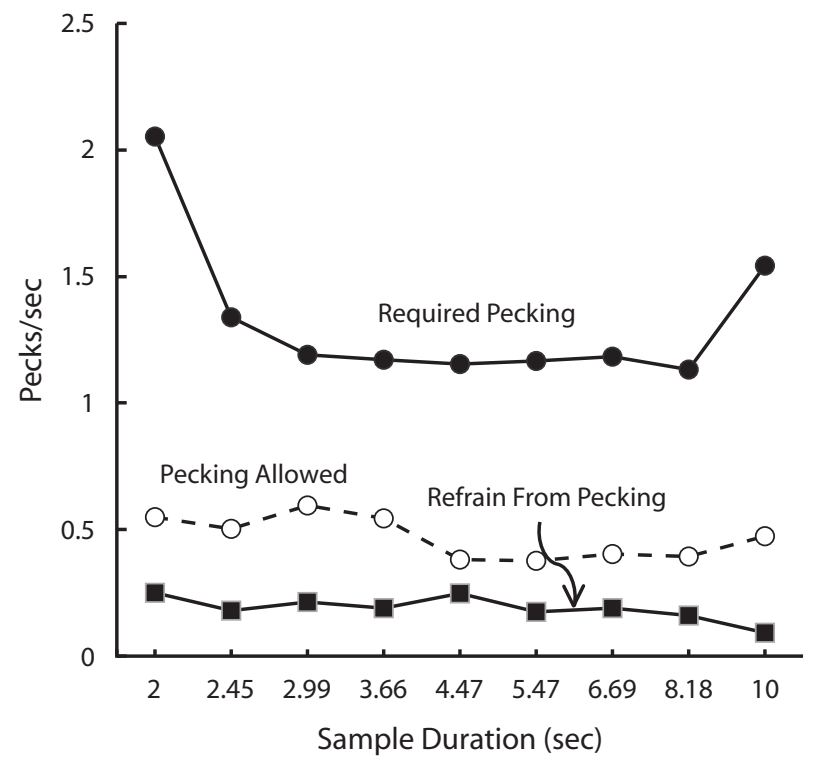

Figure 6. Rate of pecking the sample durations on test trials (including training trials during testing) for the three testing conditions: pecking required, pecking allowed, and refrain from pecking.

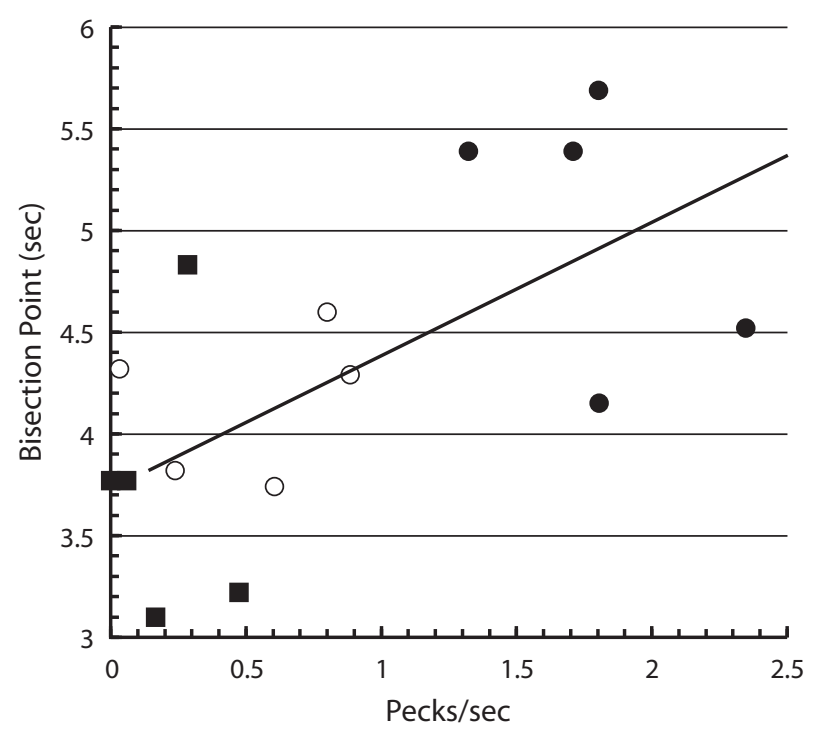

Figure 7. Correlation between bisection point and rate of sample pecking for the pecking-required condition (filled circles), the pecking-allowed condition (open circles), and the refrain-frompecking condition (filled squares) with best-fit linear function $(x=.656 y+3.73)$.

The fact that the rate of pecking is a good predictor of the shift in the bisection point suggests that it is pecking rather than the imposition of a pecking or no-pecking requirement that is responsible for the shift in the bisection point. That is, if the act of refraining from pecking had competed with the subjects' ability to time, as it appeared to do in the pecking-required condition, it should have caused the bisection point to shift to the right (relative to the pecking-allowed condition), but it did not.

The results of the present experiment replicate the results of Zentall et al. (2006), showing that imposing a pecking requirement while a pigeon is timing causes the pigeon to underestimate the passage of time relative to a requirement that the pigeon refrain from pecking. The underestimation can be seen in the shift in the bisection point of more than $1 \mathrm{sec}$, a shift slightly greater than that reported by Zentall et al.

The present results also clarify the relation between the pecking-required and the more typical pecking-allowed condition, as well as the relation between the refrain-frompecking and the pecking-allowed conditions. In keeping with the theory of timing proposed by Chaston and Kingstone (2004), the shift in the bisection point produced by the pecking requirement results from the subjective compression of time caused by the relative inattention given to cues provided by the internal clock. The presumption is that the pecking requirement requires some attention that detracts from attention to the timing task.

Interestingly, requiring that the pigeon refrain from pecking may speed up the timing process relative to the control (pecking-allowed) procedure by almost $0.5 \mathrm{sec}$. One might think that allowing the pigeon to peck or not would be less demanding of attention than requiring the pigeon to abstain from responding, but apparently it is not. 
Alternatively, the shift in bisection point produced by the requirement that the pigeon refrain from pecking may result from a different mechanism. In human research on the subjective passage of time, there is generally a response requirement that competes with the timing task. The secondary response requirement has been used to prevent subjects from counting. Thus, there has been little study of the pure timing process. Anecdotally, there is a suggestion that timing in the absence of a secondary task, especially of relatively long intervals, results in the overestimation of the passage of time. Humans routinely judge that more time has gone by than has actually passed when they are waiting for an event to take place (e.g., students waiting for the end of some lectures). If this analysis is correct, it would be difficult for an attentional theory such as the one proposed by Chaston and Kingstone (2004) to account for such an overestimation of the passage of time without positing that under normal (minimal secondary task) conditions, organisms compensate for their inattention to timing cues and calibrate their estimates of the passage of time accordingly. If they do compensate for their inattention, then under conditions involving even less distraction, they may become hyperattentive to timing cues and overestimate the passage of time.

To account for differences in the bisection point found when durations of auditory and visual stimuli were compared, Penney, Gibbon, and Meck (2000) assumed a clock model, such as the one described by Gibbon (1991), and suggested that visual signals caused the clock to run at a slower rate than auditory signals. Thus, an alternative to Chaston and Kingstone's (2004) hypothesis of inattention to the clock cues is that the clock runs slower when the subject is more active (i.e., is pecking).

If pigeons are trained with pecking-required and refrain-from-pecking conditions, why do they not just recalibrate their temporal scale? If, for example, $2 \mathrm{sec}$ while pecking feels like $1.8 \mathrm{sec}$, and $10 \mathrm{sec}$ feels like $9 \mathrm{sec}$, the bisection point could still be at about $4.1 \mathrm{sec}$ (as it was for the pecking-allowed condition in the present study), but it would feel like $3.7 \mathrm{sec}$. Penney et al. (2000) suggested that during training, subjects develop a single memory for short stimuli and a single memory for long stimuli that represent the average of the subjective durations of the short and long stimuli. On test trials involving the intermediate durations, the duration on the current trial would be judged relative to the average memory representation established during training, and the shift in bisection point would be consistent with an attentional account.

The results of the present experiment confirm and extend the results of Zentall et al. (2006) and are consistent with findings from the human timing literature. When pi- geons are required to peck at a light that they are also timing, they tend to underestimate the passage of time relative to when they are required to refrain from pecking. Allowing them to peck (or not peck) results in an intermediate timing function.

Note-This article was accepted by the previous editorial team, when Shepard Siegel was Editor.

\section{AUTHOR NOTE}

This research was supported by National Institute of Mental Health Grant MH 63726. Correspondence concerning this article should be sent to T. R. Zentall, Department of Psychology, University of Kentucky, Lexington, KY 40506-0044 (e-mail: zentall@uky.edu).

\section{REFERENCES}

Chastain, G., \& Ferraro, F. R. (1997). Duration ratings as an index of processing resources required for cognitive tasks. Journal of General Psychology, 124, 49-76.

Chaston, A., \& Kingstone, A. (2004). Time estimation: The effect of cortically mediated attention. Brain \& Cognition, 55, 286-289.

Church, R. M. (1978). The internal clock. In S. H. Hulse, H. Fowler, \& W. K. Honig (Eds.), Cognitive processes in animal behavior (pp. 277-310). Hillsdale, NJ: Erlbaum.

Gibbon, J. (1986). The structure of subjective time: How it flies. In G. H. Bower (Ed.), The psychology of learning and motivation (Vol. 12, pp. 105-135). Orlando: Academic Press.

Gibbon, J. (1991). The origins of scalar timing. Learning \& Motivation, 22, 3-38.

GibBon, J., \& CHURCH, R. M. (1984). Sources of variance in an information processing theory of timing. In H. L. Roitblat, T. G. Bever, \& H. S. Terrace (Eds.), Animal cognition (pp. 465-488). Hillsdale, NJ: Erlbaum.

Hoekstra, S. J. (2005, May). “Time flies when you're having fun”: Cognitive load and perceptions of time. Paper presented at the meeting of the Midwestern Psychological Association, Chicago.

Kraemer, P. J., Brown, R. W., \& Randall, C. K. (1995). Signal intensity and duration estimation in rats. Behavioural Processes, 34, 265-268.

Penney, T. B., Gibbon, J., \& Meck, W. H. (2000). Differential effects of auditory and visual signals on clock speed and temporal memory. Journal of Experimental Psychology: Human Perception \& Performance, 26, 1770-1787.

Platt, J. R., \& Davis, E. R. (1983). Bisection of temporal intervals by pigeons. Journal of Experimental Psychology: Animal Behavior Processes, 9, 160-170.

StuBbs, D. A. (1976). Scaling of stimulus duration by pigeons. Journal of the Experimental Analysis of Behavior, 26, 15-25.

WILKIE, D. M. (1987). Stimulus intensity affects pigeons' timing behavior: Implications for an internal clock model. Animal Learning \& Behavior, 15, 35-39.

ZAKAY, D. (1993). Time estimation methods: Do they influence prospective duration estimates? Perception, 22, 91-101.

Zentall, T. R., Friedrich, A. M., \& Clement, T. S. (2006). Required pecking alters judgments of the passage of time by pigeons. Psychonomic Bulletin \& Review, 13, 1038-1042.

(Manuscript received September 13, 2007; revision accepted for publication October 9, 2007.) 